\title{
Comparison of cervical cancer screening by self-sampling papillomavirus test versus pap-smear in underprivileged women in France
}

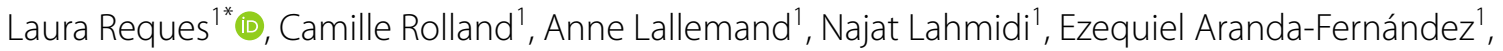
Antonio Lazzarino ${ }^{2}$, Julie Bottero ${ }^{3}$, Françoise Hamers ${ }^{4}$, Christine Bergeron ${ }^{5}$, Ken Haguenoer ${ }^{6,7}$, Guy Launoy ${ }^{8}$ and Niklas Luhmann ${ }^{1}$

\begin{abstract}
Background: The purpose of this study was to compare cervical cancer screening by pap smear (PS) versus preliminary HPV testing based on self-collected samples (SC-HPV).

Methods: Interventional study among underprivileged women from 25 to 65 years old in four French cities. The control group (CG) was referred for a PS. The experimental group (EG) conducted a SC-HPV test followed by a PS in case of positivity. Differences on screening completion and cytological abnormalities were analysed by logistic and Cox regression.
\end{abstract}

Results: 383 women were assigned to the EG and 304 to the CG. The screening completion proportion was 39.5\% in the CG compared to $71.3 \%$ in the $E G(H R=2.48$ (Cl 95\% [1.99-3.08]; $p<0.001)$. The proportion of cytological abnormalities was $2.0 \%$ in the $C G$ and $2.3 \%$ in the $E G(O R=1.20(\mathrm{Cl} 95 \%[0.42-3.40] ; \mathrm{p}=0.7)$. The proportion of participants lost to follow-up was $60.5 \%$ in the CG and $63.2 \%$ in the EG HPV positive $(p=0.18)$.

Conclusion: Providing an SC-HPV-test increased the participation of underprivileged women in CCS. Nevertheless, the significant number of lost to follow-up in both groups can undermine the initial benefits of the strategy for HPV positive women.

Registration: Clinicaltrials.gov: NCT03118258.

Keywords: SC-HPV, Papillomavirus, Cervical cancer, Screening, Vulnerability

\section{Background}

Human papillomavirus (HPV) is the most common sexually transmitted infection [1]. In most cases, it is asymptomatic and can regress spontaneously. Nevertheless, an infection by a high-risk genotype (HR-HPV) can persist

*Correspondence: requeslaura@hotmail.com

${ }^{1}$ Médecins du Monde, 62 rue Marcadet, 75018 Paris, France

Full list of author information is available at the end of the article and might result in precancerous lesions that might turn into cervical cancer after 5 to 20 years [1-4].

Cervical cancer is the most frequently diagnosed type of cancer among women in 28 countries and the leading cause of cancer-related mortality in 42 countries, most of which are located in Sub-Saharan Africa and South-East Asia [5].

In France, cervical cancer affects nearly 3000 women and causes around 1100 deaths every year [6]. 
Currently, pap smear (PS) is the primary cervical cancer screening (CCS) test used to detect precancerous lesions and early-stage cervical cancer [3, 7]. European guidelines set the acceptable level of coverage at $70 \%$ and the desired level at $85 \%$ [8]. National three-year coverage rate of PS screening is estimated to be insufficient (60\%) [9].

The French national cervical cancer screening program relies directly on health professionals providing gynaecological services to the women concerned, mainly gynaecologists, general practitioners and midwives. The strategy is accompanied by communication campaigns and individual invitations for target population (women between 25 and 65 years old). Cytology exams and HPV tests are covered $100 \%$ for insured women. This strategy ostracises women without health coverage or experimenting health care access difficulties. Actually, it is estimated that women with limited access to the healthcare system, women of low socioeconomic status, and women living in economically depressed areas are less likely to have access to CCS $[10,11]$.

Data from Médecins du Monde (MdM) indicated that nearly $67 \%$ of women between the ages of 25 and 65 attending to MdM programmes in France had never performed a PS [12]. This finding has been supported by other studies [13]. In addition, these underprivileged women often come from countries with the highest cervical cancer incidence and mortality rates [5]. The concept "underprivileged" joins the notions of low social and economic status, including low income, low educational level, migration status, unemployment, shelter conditions, minorities, absence of social insurance or marginalisation.

HPV testing has been shown to be more sensitive than the PS exam [14-16]. Self-collected samples for HPV testing (SC-HPV) have been found to be as sensitive as clinically-collected samples [17]. Several international studies described the SC-HPV technique as easier, less painful, less bothersome and faster than a conventional PS $[18,19]$. Based on these findings, several Western countries have recently incorporated HPV testing into their CCS strategy. In 2015, the European Commission recommended to include a twophase HPV testing strategy in an organised screening programme [8].

The purpose of this study was to compare the proportion of screening test completion and the proportion of cytological abnormalities detected using two different strategies within underprivileged women in France. These strategies included an individual preventive medical consultation followed by either a referral to a partner facility for a PS or preliminary SCHPV testing.

\section{Methods \\ Study type}

Interventional, multicentre, comparative, and randomised research focused on four types of programmes: CASO (Reception, Healthcare, and Orientation Centres), CAOA (Reception, Orientation, and Support Centres), Squats/Slums, and Sex Worker programmes (SWP) in four cities (Lyon, Bordeaux, Rouen, and Paris).

MdM's CASO/CAOA are structures conceived to facilitate access to healthcare rights and prevention for people experimenting socioeconomic difficulties. They have permanent and voluntary staff, including doctors, nurses, psychologists, social workers and community agents. Users are mainly newly arrived migrants, but also other profiles with social factors of vulnerability (like homeless, unemployed and drug users). People come spontaneously to the centres through multiple community communication channels.

The other programs include outreach actions, particularly in vulnerable settlements (squats and slums) and in sex workers place of practice. In the slums, MdM offers on-site medical and prevention consultations accompanied by referrals to other healthcare structures and sensitization about contraception, family planning and prenatal care. Programs with sex workers address the topics of sexually transmitted infections, hepatitis, HIV, unwanted pregnancies, violence, psychological suffering and advocacy.

Programmes participating in the study were selected to have representative profiles and locations according to the flux of women in the targeted age range and to the presence of sexual and reproductive activities in the programmes' current line-up of services.

The study was conducted from March 2017 to December 2018.

\section{Inclusion criteria}

All women between the ages of 25 and 65 who had not had a PS in the past three years were included in the study. Exclusion criteria included study participation refusal, having a history of a complete hysterectomy or the absence of sexual intercourse in the past.

\section{Participant screening process}

Eligible women were offered an individual sexual and reproductive health $(\mathrm{SRH})$ consultation which included an adapted and individual consultation informing about HPV infections, cervical cancer, the importance of gynaecological care and screening strategies. An interpreter or healthcare mediator was also available. At the 
end of the consultation, women were separated into two groups: (1) The "PS" control group (CG) (in which study participants were referred towards partner associations and institutions to have a PS); (2) The "SC-HPV" experimental group (EG) (in which HPV was tested using a self-collected sample, followed by a referral to partner associations for a PS if the HPV results were positive or non-interpretable/missing). EG patients were provided with a SC-HPV kit and given the choice of either collecting the sample on site in a private room or at home (in the case of menstruation or if the patient declined to collect the sample on site). Patients were given their HPV results two weeks later, and they were scheduled for a followup appointment. If results were positive, patients were directed to partner centres to get a PS. Women whose HPV tests were positive received a reminder phone-call. Patients assigned to CG benefited systematically from a HPV test when cytological abnormalities were detected in the PS.

Women who had not completed an HPV test or PS four months after their appointment were considered lost to follow-up.

\section{Sample size}

Sample size calculation was based on risk $\mathrm{a}=5 \%$ and power of $80 \%$, a proportion of CCS completion of $80 \%$ in the EG and $40 \%$ in the CG, and a proportion of cytological abnormalities of $2.5 \%$ in the CG and $4 \%$ in the EG. The number of participants was estimated at 1258 to answer to both objectives.

\section{Randomisation}

Participants in each programme were randomly assigned over one-month periods. Each month in which participants were offered an SC-HPV was followed by a period in which participants were not offered this option.

\section{Biological analyses}

The test selected for the study was the ABBOTT Real Time High Risk HPV test (real-time PCR test detecting 14 HPV genotypes: $16,18,31,33,35,39,45,51,52,56$, $58,59,66$, and 68 ). All partner facilities conducted liquidbased cytologies.

\section{Data collection}

Participants' medical and social data were collected through a questionnaire administered by trained professionals. These data were entered into a secure "electronic patient record" tool. MdM's partner structures submitted the results of the PS exams via confidential mail.

\section{Evaluation criteria}

Screening completion rate was defined as the proportion of women who have a PS done in the CG and the proportion of women who had a negative HR-HPV test or had a PS done if the HR-HPV test was positive in the EG.

As cytological abnormalities we considered ASC-US, LSIL and HSIL.

\section{Statistical analysis}

The descriptive analysis was conducted based on the demographic, socio-economic, and clinical variables in each procedure group. Comparability of the groups was evaluated using Chi-2 tests, ANOVA tests for categorical variables whereas $t$-Student tests for continuous variables. The comparison between the rate of screening completion and the number of cytological lesions was conducted using logistic and Cox regressions. All analyses were repeated with another sample that only included data from CASO/CAOA programmes. Statistical analysis was done using the software Stata 15 [20].

\section{Ethical considerations}

This research project was approved by the Île de France IV Institutional Review Board (IRB). The study was conducted in compliance with the ethical principles of the Helsinki Declaration. All participants were informed of the study's objectives and design, and their participation was voluntary after providing verbal informed consent. The protocol was registered in clinicaltrials.gov.

\section{Results}

The study flowchart is depicted in Fig. 1. Out of the 799 participants in the study who received a gynaecological consultation, 112 (15.3\%) were not eligible for the intervention (67 were up to date with their CCS, 13 had never had sexual relations, and 8 had had a complete hysterectomy). The final population was 687 women, 304 of which were assigned to the CG (PS) and 383 to the EG (HPV self-sample). The EG was slightly larger because of a higher participation rate among participants from the SWP in Paris during the months when SC-HPV was offered.

In the CG, out of the 304 women who were referred for a PS, 120 (39.5\%) followed through with the exam and 184 (60.5\%) were lost to follow up. Out of the 120 PS conducted, 11 cytological abnormalities were detected: 8 ASC-US ( 3 of which were caused by an HPV infection), 2 LSIL, and 1 HSIL.

In the EG, out of the 383 women, 365 (95.3\%) submitted SC-HPV, 15 (3.9\%) were lost to follow-up, and three (0.8\%) declined to submit a self-sample. Out of the HPV tests that were completed, 226 were negative, 127 were positive, 9 could not be interpreted, and 3 were missing. 
Flowchart 1 Trial pro file in all study participants

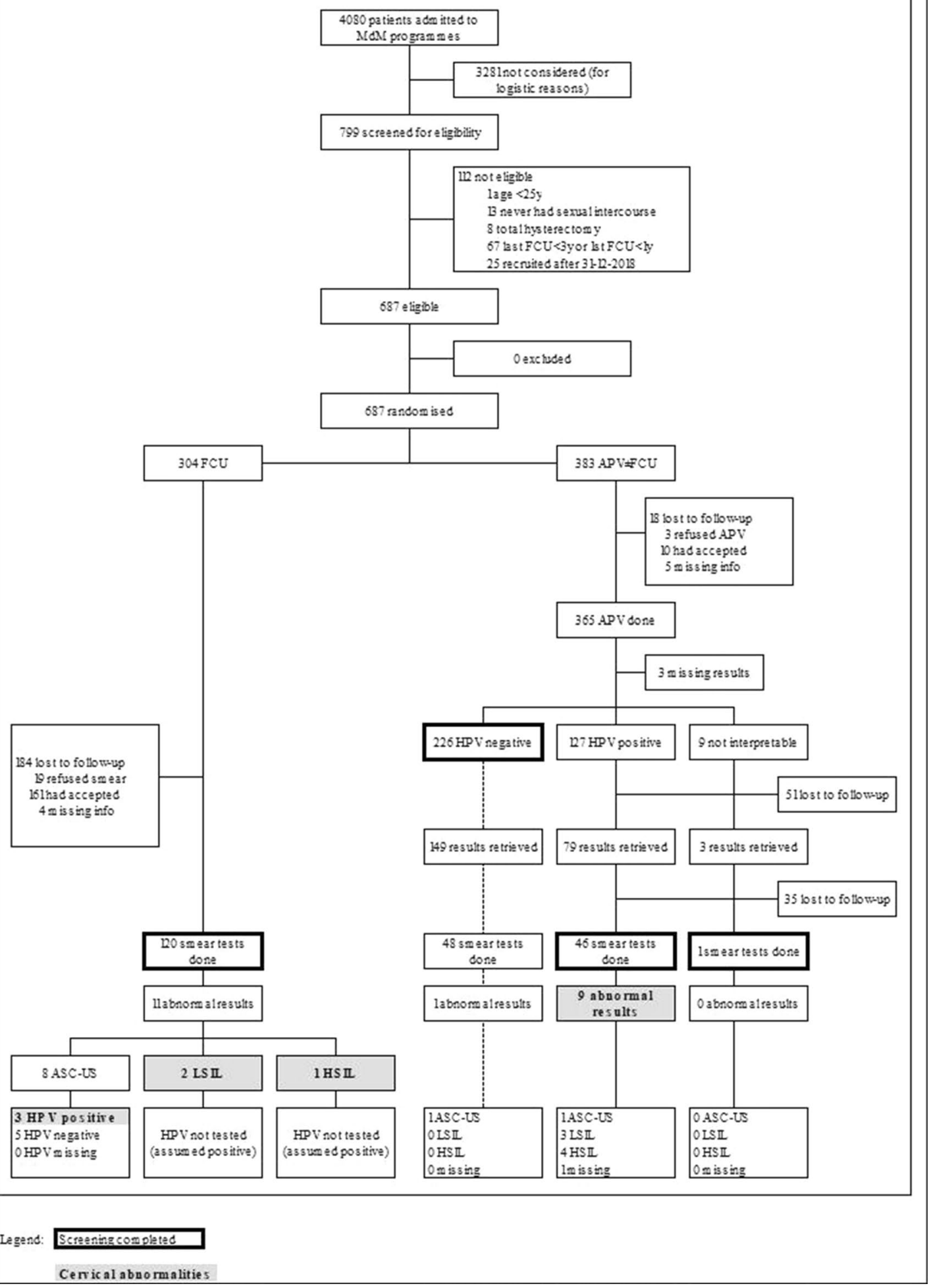

Fig. 1 Study flowchart 
$34.4 \%$ of the HPV-tests done were positive. Out of the 136 women who tested positive for HPV or whose test could not be interpreted, 47 (34.6\%) had a PS and 9 cytological abnormalities were detected (1 ASC-US, 3 LSIL, and 5 HSIL).

In the CG, 184 women were lost to follow-up after they were given a referral for a PS (60.5\%). In the EG, 18 women were lost to follow-up before they could submit an SC-HPV (4.7\%). In addition, out of the 136 women whose HPV results were positive or could not be interpreted, 35 were lost to follow-up after they were referred for a PS $(63.2 \%$ of women with an indication to have a PS).

Table 1 presents a description of the characteristics of the participants by group: $54.7 \%$ had completed up to either primary or secondary school, $62.5 \%$ had been in France for under a year, $67.7 \%$ did not have a reported employment, $73.4 \%$ were undocumented, and $68.3 \%$ did not have health insurance. $40 \%$ needed interpreting services. There were no statistically significant differences between the main covariables in the two groups.

With respect to the proportion of screening completion, the participants in the EG were approximately twice as likely to have access to the test as the CG (39.5\% compared to $71.3 \%, p<0.001$ ), with a risk ratio (RR) of 1.80 : CI 95\% [1.55-2.10]; $p<0.001$.

Figure 2 shows a forest plot including an analysis with respect to the screening test completion. Among the women who completed the screening tests, the process took an average of 18.6 days (SD: 34.5$)$ for the CG and 9.5 days (SD: 23.8$)$ for the EG $(p<0.001)$.

The hazard ratio (HR) for the screening test completion rate for the EG compared to the CG was 2.48 (CI 95\% [1.99-3.08]; $p<0.001)$. The analysis of the sub-groups shows that the effect was not modified by the study's other covariables.

Figure 3 shows a forest plot that includes an analysis of the overall data set and that of each sub-group with respect to the number of cytological abnormalities

Table 1 Characteristics of study participants by procedure group

\begin{tabular}{|c|c|c|c|c|c|c|c|}
\hline \multirow[t]{3}{*}{ Variable and category } & \multirow{2}{*}{\multicolumn{2}{|c|}{ Total }} & \multicolumn{4}{|c|}{ Procedure group } & \multirow[t]{3}{*}{$p$ value } \\
\hline & & & \multicolumn{2}{|c|}{ Control } & \multicolumn{2}{|c|}{ Experimental } & \\
\hline & $\mathrm{N}=6$ & & $\mathbf{N}=3$ & & $\mathbf{N}=3$ & & \\
\hline Age & 41.0 & (SD 10.1) & 39.7 & (SD 9.9) & 42.0 & (SD 10.2) & 0.004 \\
\hline Educational level (\%) & & & & & & & 0.81 \\
\hline Primary school or less & 27.0 & $(183 / 678)$ & 27.7 & $(83 / 300)$ & 26.5 & $(100 / 378)$ & \\
\hline Secondary school & 54.7 & $(371 / 678)$ & 53.3 & $(160 / 300)$ & 55.8 & $(211 / 378)$ & \\
\hline University & 18.3 & $(124 / 678)$ & 19.0 & $(57 / 300)$ & 17.7 & $(67 / 378)$ & \\
\hline Time spent in France (\%) & & & & & & & 0.008 \\
\hline$<3$ months & 32.5 & $(217 / 668)$ & 33.4 & $(101 / 302)$ & 31.7 & $(116 / 366)$ & \\
\hline 3-12 months & 30.5 & $(204 / 668)$ & 35.4 & $(107 / 302)$ & 26.5 & $(97 / 366)$ & \\
\hline$>12$ months & 37.0 & $(247 / 668)$ & 31.1 & $(94 / 302)$ & 41.8 & $(153 / 366)$ & \\
\hline Employment (\%) & 27.4 & $(180 / 658)$ & 19.1 & $(57 / 298)$ & 34.2 & $(123 / 360)$ & $<0.001$ \\
\hline Migration status (\%) & & & & & & & 0.60 \\
\hline Documented & 16.9 & $(113 / 669)$ & 15.0 & $(45 / 301)$ & 18.5 & $(68 / 368)$ & \\
\hline Undocumented & 73.4 & $(491 / 669)$ & 74.4 & $(224 / 301)$ & 72.6 & $(267 / 368)$ & \\
\hline In the process of becoming legal & 8.4 & $(56 / 669)$ & 9.3 & $(28 / 301)$ & 7.6 & $(28 / 368)$ & \\
\hline Unknown & 1.3 & $(9 / 669)$ & 1.3 & $(4 / 301)$ & 1.4 & $(5 / 368)$ & \\
\hline Need for an interpreter (\%) & 40.3 & $(273 / 677)$ & 33.6 & $(100 / 298)$ & 45.6 & $(173 / 379)$ & 0.001 \\
\hline Health coverage (\%) & & & & & & & 0.17 \\
\hline None & 68.3 & $(457 / 669)$ & 72.7 & $(218 / 300)$ & 64.8 & $(239 / 369)$ & \\
\hline PUMa (French universal healthcare regime) & 4.6 & $(31 / 669)$ & 4.7 & $(14 / 300)$ & 4.6 & $(17 / 369)$ & \\
\hline Top-off insurance & 6.7 & $(45 / 669)$ & 6.3 & $(19 / 300)$ & 7.0 & $(26 / 369)$ & \\
\hline AME (healthcare social worker) & 19.6 & $(131 / 669)$ & 16.0 & $(48 / 300)$ & 22.5 & $(83 / 369)$ & \\
\hline Other & 0.7 & $(5 / 669)$ & 0.3 & $(1 / 300)$ & 1.1 & $(4 / 369)$ & \\
\hline Number of dependent children & 1.1 & $(S D 1.3)$ & 1.1 & (SD 1.3) & 1.1 & $(S D 1.2)$ & 1.00 \\
\hline Screening test completion (\%) & 57.2 & $(393 / 687)$ & 39.5 & $(120 / 304)$ & 71.3 & $(273 / 383)$ & $<0.001$ \\
\hline Cytological abnormalities detected (\%) & 2.2 & $(15 / 687)$ & 2.0 & $(6 / 304)$ & 2.3 & $(9 / 383)$ & 0.74 \\
\hline
\end{tabular}




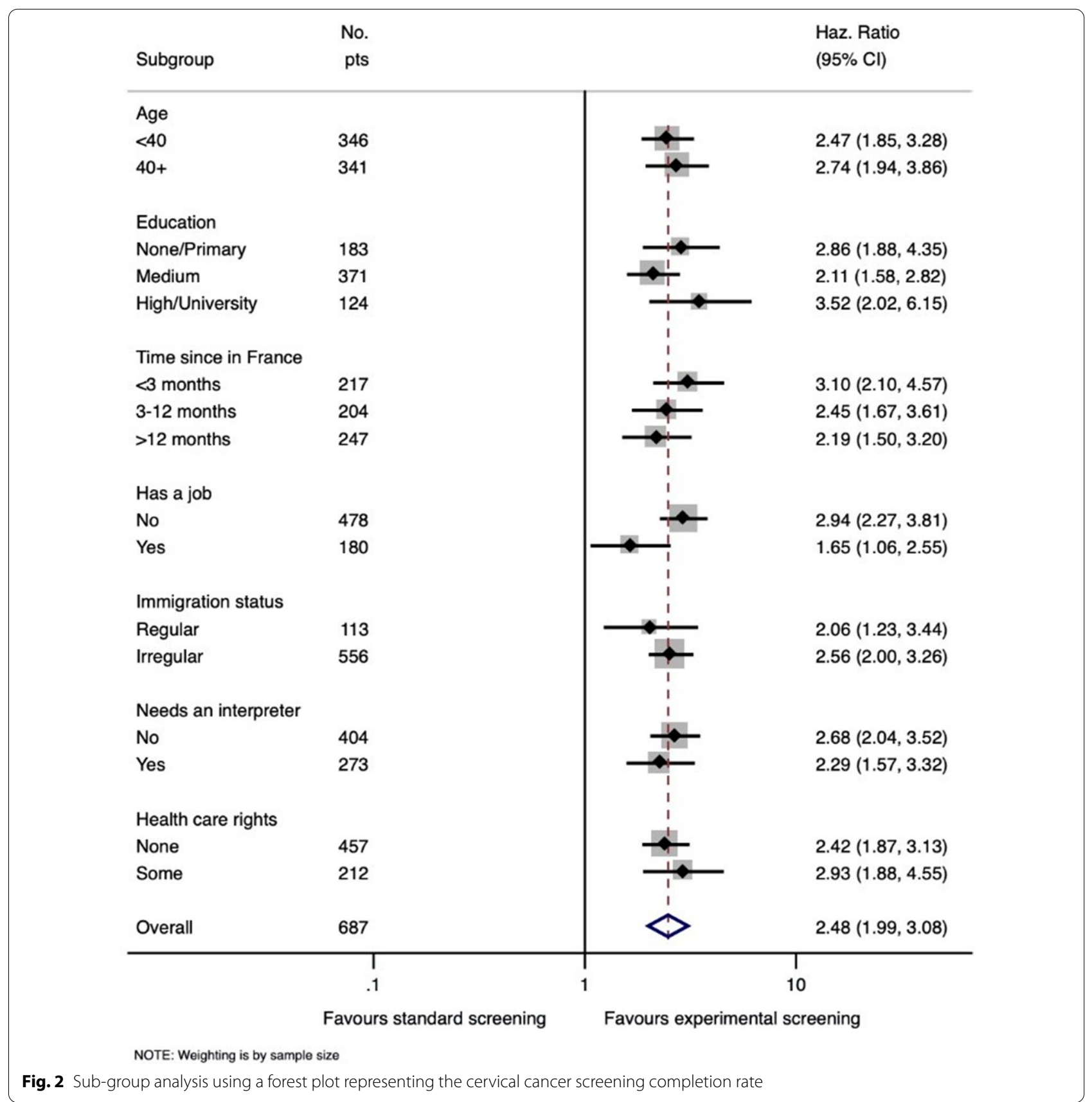

detected. In the CG, $2.0 \%$ of women had cytological abnormalities associated with an HPV infection, and $2.3 \%$ in the EG, with an OR of $1.20(0.42-3.40), p=0.7$. The power of this difference in proportions was weak (0.056). The effect was not modified by other study's covariables.

All analyses were also conducted using a sample that only included participants from programmes with more consistent results (CASO/CAOA). Both groups were well balanced and their results do not differ from the results of the entire sample in terms of screening performance, number of participants lost to follow-up, screening test completion, and cytological abnormalities detected (Appendices 1, 2, 3, 4).

\section{Discussion}

The option of using a SC-HPV is an effective alternative for improving screening access and coverage among underprivileged women. Nevertheless, the number of 


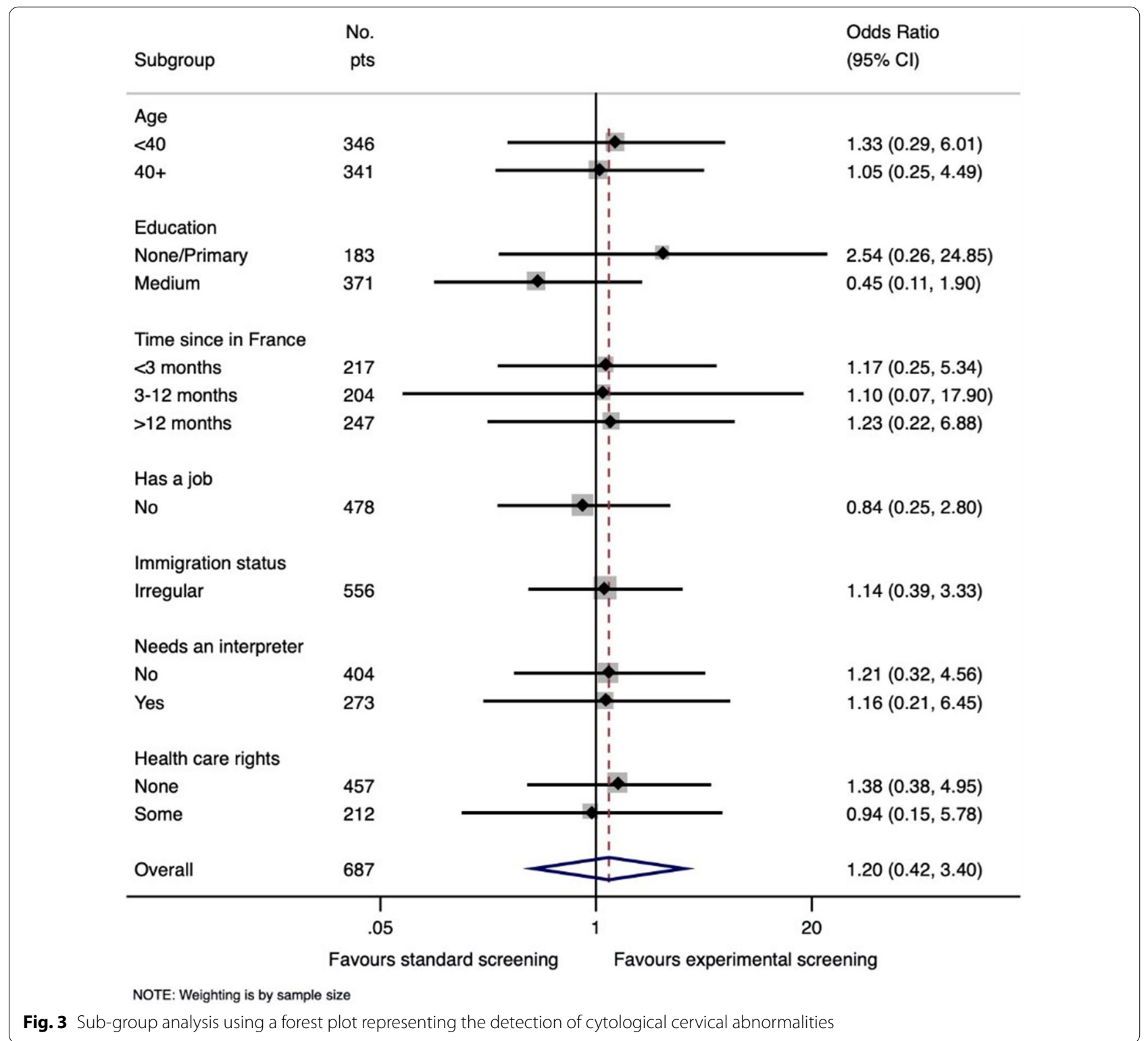

required visits makes it difficult to complete the screening process, which limits the strategy's benefit.

The profile of the women who participated in the study varies widely in terms of age, origins, and other sociodemographic aspects. This profile corresponds to the characteristics of the women who participate in MdM's programmes, who are mainly immigrants, homeless, sex workers, and drug users. These groups have limited access to housing and healthcare. In many cases, they are also not legally employed and undocumented [12]. Sociocultural factors, such as the individual's country of origin, language, religion, marital and inter-familial relationships, also influence access to CCS, as it has been shown in the literature [21-27].
$\mathrm{SC}-\mathrm{HPV}$ is an effective time and resource-saving strategy as it helps engaging women at preliminary stages of the screening process. This strategy has been described to be especially popular among women living in vulnerable situations $[14,28-30]$ and just as sensitive and slightly less specific than testing for HPV with a cervical sample taken by a physician $[17,31,32]$. In our study, the technique also had a high level of acceptability, as only $0.8 \%$ of women declined to submit a sample. In addition, the percentage of tests found to be invalid due to their transportation conditions, the quantity or quality of the material, or sampling errors was very low $(<1 \%)$. This also shows the excellent performance of these tests in real conditions and among the women participating in the study. 
In July 2019, the French National Authority for Health recommended that HPV testing be included in France's CCS strategy for women over 30 who had not been screened or who had received insufficient screening [33]. Our results show the ability of this technique to provide underprivileged women with access to CCS.

Compared to national figures, which estimate that $15-20 \%$ of women between the ages of 25 and 65 have this type of virus [10], this study showed potentially higher rates for carcinogenic HPV infection (35\%). A similar finding is reported in the scientific literature, which found that higher proportion of HPV infection among sex works [34-36] and immigrant communities. The prevalence of the virus in the women's entourage, exposure to high-risk practises, and a decreased use of prevention methods could explain these findings.

To complete the entire screening pathway, women had to attend three appointments (prevention consultation, an appointment at the partner centre for a PS exam, and an appointment to receive the results). This number might have been even higher if women needed to receive additional tests, undergo a colposcopy, or receive treatment for their lesions. In the EG, the two-stage screening strategy (HPV screening as the primary exam, delivery of the HPV test results, and PS), shortened the screening process for women whose HPV results were negative but added an extra visit in the event of positive HPV results. As a result, one of the most notable findings of our study was the high number of women lost to follow-up. It should be noted that this took place in both study groups, regardless of whether or not the women knew their HPV results. Results delivery delays (10 days for the HPV tests and a few weeks for the PS exams) added another barrier. The high number of participants who were lost to followup underscores how difficult it is to treat these women and could undermine the benefits gained by increasing primary screening coverage by using SC-HPV.

On the other hand, it is clearly beneficial for women to know that they tested negative for HR-HPV. Not only is it a source of relief, but it also means they can complete their screening process more quickly. Moreover, the high level of acceptability and logistical simplicity of this technique could also increase long-term participation in screening programmes.

In this sense, the benefits of HPV test approach are evident and the endpoint "participation" is absolutely clear, as the self-collected HPV test offer much more protection.

Several studies have shown that the long duration of the screening process represents a barrier to completing it within underprivileged women [36, 37]. In addition, a lack of knowledge and awareness, personal reticence, lack of time, absence of family support, need for marital consent, language barriers, travel issues, limited access to healthcare facilities, anxiety about receiving a cancer diagnosis and its consequences have also been mentioned as frequent barriers to screening access [35, 38, 39]. However, reducing the number of appointments, providing rapid testing options, points of care and improving the accessibility of healthcare facilities improves screening completion rates and patient treatment [38, 39].

Even though some of the barriers are directly related to the access to healthcare facilities, also essential for completing the screening programmes are socio-cultural determinants, understanding of the message plus the individual's own risk perception. This reality highlights the importance of counselling and interpreting services.

\section{Limitations}

This study has a certain number of limitations. First, monthly randomisation was selected in collaboration with teams on the field together with the scientific committee. Choosing to alternate between one-month periods was easier to follow and helped to limit bias related to seasonal variations. In the SWP in Paris, where the sex worker community is highly cohesive, offering SC-HPV during specific periods encouraged the women to visit the healthcare structures. Nevertheless, this pattern does demonstrate the benefit of this screening strategy for this population.

In addition, there were low participation rates in the Squat programmes and SWP in Rouen. This fact can be due to the different approach of the activities (CASO/ CAOA are fix and stables programs with a constant influx of patients and potential candidates while Squat and SWP are based on an outreach approach, which makes mobilisation more difficult).

To limit these potential sources of bias, we decided to conduct a supplementary analysis that only included data from the CASO/CAOA (77\% of the sample), obtaining very similar results to the full dataset.

The study was underpowered for the outcome "proportion of cytological abnormalities", as the study had to stop before sample size completion due to budget constraints.

In addition, it would have been better to measure the completion rate based on the number of retrieved results, which would have ensured that the women knew their status. Unfortunately, this information was available for the results of the HPV tests (which were conducted and collected within MdM facilities), but not for the results of the PS exams (which were conducted and collected in a variety of partner facilities).

Finally, it would be beneficial to offer a holistic SRH strategy to these populations, including vaccinations and testing for other STIs, such as HIV and hepatitis. 


\section{Conclusions}

Our study is the first to provide information about different CCS strategies for underprivileged women in France.

SC-HPV strategy presented a higher proportion of screening test completion and cytological abnormalities detection (with difference of proportions non-statistically significant for the second conclusion).

Providing participants with a SC-HPV kit improved the participation of underprivileged women in CCS. Nevertheless, the significant number of lost to follow-up in both groups can undermine the initial benefits of the strategy for HPV positive women.
It is important to better understand the barriers to screening encountered within this population and thus to design more adapted, differentiated, and appropriate strategy to reduce inequalities.

\section{Appendix 1}

See Table 2.

Table 2 Characteristics of study participants based on procedure group: CASO and CAOA programmes only

\begin{tabular}{|c|c|c|c|c|c|c|c|}
\hline \multirow[t]{3}{*}{ Variable and category } & \multirow{2}{*}{\multicolumn{2}{|c|}{ Total }} & \multicolumn{4}{|c|}{ Procedure group } & \multirow[t]{3}{*}{$p$ value } \\
\hline & & & & \multicolumn{2}{|c|}{ Experimental } & \\
\hline & $\mathbf{N}=$ & & $\mathrm{N}=2$ & & $\mathbf{N}=$ & & \\
\hline Age & 38.7 & (SD 9.9) & 38.6 & (SD 9.8) & 38.8 & (SD 10.0) & 0.83 \\
\hline Educational level (\%) & & & & & & & 0.81 \\
\hline Primary school or less & 29.4 & $(144 / 490)$ & 29.3 & $(72 / 246)$ & 29.5 & $(72 / 244)$ & \\
\hline Secondary school & 47.1 & $(231 / 490)$ & 48.4 & $(119 / 246)$ & 45.9 & $(112 / 244)$ & \\
\hline University & 23.5 & $(115 / 490)$ & 22.4 & $(55 / 246)$ & 24.6 & $(60 / 244)$ & \\
\hline Time spent in France (\%) & & & & & & & 0.20 \\
\hline$<3$ months & 43.2 & $(210 / 486)$ & 39.9 & $(99 / 248)$ & 46.6 & $(111 / 238)$ & \\
\hline 3-12 months & 37.0 & $(180 / 486)$ & 40.7 & $(101 / 248)$ & 33.2 & $(79 / 238)$ & \\
\hline$>12$ months & 19.8 & $(96 / 486)$ & 19.4 & $(48 / 248)$ & 20.2 & $(48 / 238)$ & \\
\hline Employment (\%) & 13.6 & $(66 / 484)$ & 12.1 & $(30 / 247)$ & 15.2 & $(36 / 237)$ & 0.33 \\
\hline Migration status (\%) & & & & & & & 0.89 \\
\hline Documented & 16.6 & $(81 / 487)$ & 15.8 & $(39 / 247)$ & 17.5 & $(42 / 240)$ & \\
\hline Undocumented & 71.7 & $(349 / 487)$ & 72.1 & $(178 / 247)$ & 71.2 & $(171 / 240)$ & \\
\hline In the process of becoming legal & 10.3 & $(50 / 487)$ & 10.9 & $(27 / 247)$ & 9.6 & $(23 / 240)$ & \\
\hline Unknown & 1.4 & $(7 / 487)$ & 1.2 & $(3 / 247)$ & 1.7 & $(4 / 240)$ & \\
\hline Need for an interpreter (\%) & 18.3 & $(89 / 487)$ & 20.1 & $(49 / 244)$ & 16.5 & $(40 / 243)$ & 0.30 \\
\hline Health coverage (\%) & & & & & & & 0.20 \\
\hline None & 83.8 & $(409 / 488)$ & 82.6 & $(204 / 247)$ & 85.1 & $(205 / 241)$ & \\
\hline PUMa (French universal healthcare regime) & 3.5 & $(17 / 488)$ & 4.0 & $(10 / 247)$ & 2.9 & $(7 / 241)$ & \\
\hline Top-off insurance & 4.7 & $(23 / 488)$ & 3.6 & $(9 / 247)$ & 5.8 & $(14 / 241)$ & \\
\hline AME (healthcare social worker) & 7.2 & $(35 / 488)$ & 9.3 & $(23 / 247)$ & 5.0 & $(12 / 241)$ & \\
\hline Other & 0.8 & $(4 / 488)$ & 0.4 & $(1 / 247)$ & 1.2 & $(3 / 241)$ & \\
\hline Number of dependent children & 1.2 & $(S D 1.3)$ & 1.1 & $(\mathrm{SD} 1.3)$ & 1.3 & $(S D 1.3)$ & 0.31 \\
\hline Screening test completion (\%) & 57.3 & $(285 / 497)$ & 38.8 & $(97 / 250)$ & 76.1 & $(188 / 247)$ & $<0.001$ \\
\hline Cytological abnormalities detected (\%) & 1.8 & $(9 / 497)$ & 1.6 & $(4 / 250)$ & 2.0 & $(5 / 247)$ & 0.72 \\
\hline
\end{tabular}

The estimates are expressed as mean with the standard deviation (SD) in parentheses or proportions with the absolute numbers between parentheses. The $p$ values for the categorical and binary variables were calculated using Pearson's chi-squared test. $P$ values for the continuous variables were calculated using the two-sample t-test 


\section{Appendix 2. Screening flow chart by procedure group:: CASO and CAOA programmes only}

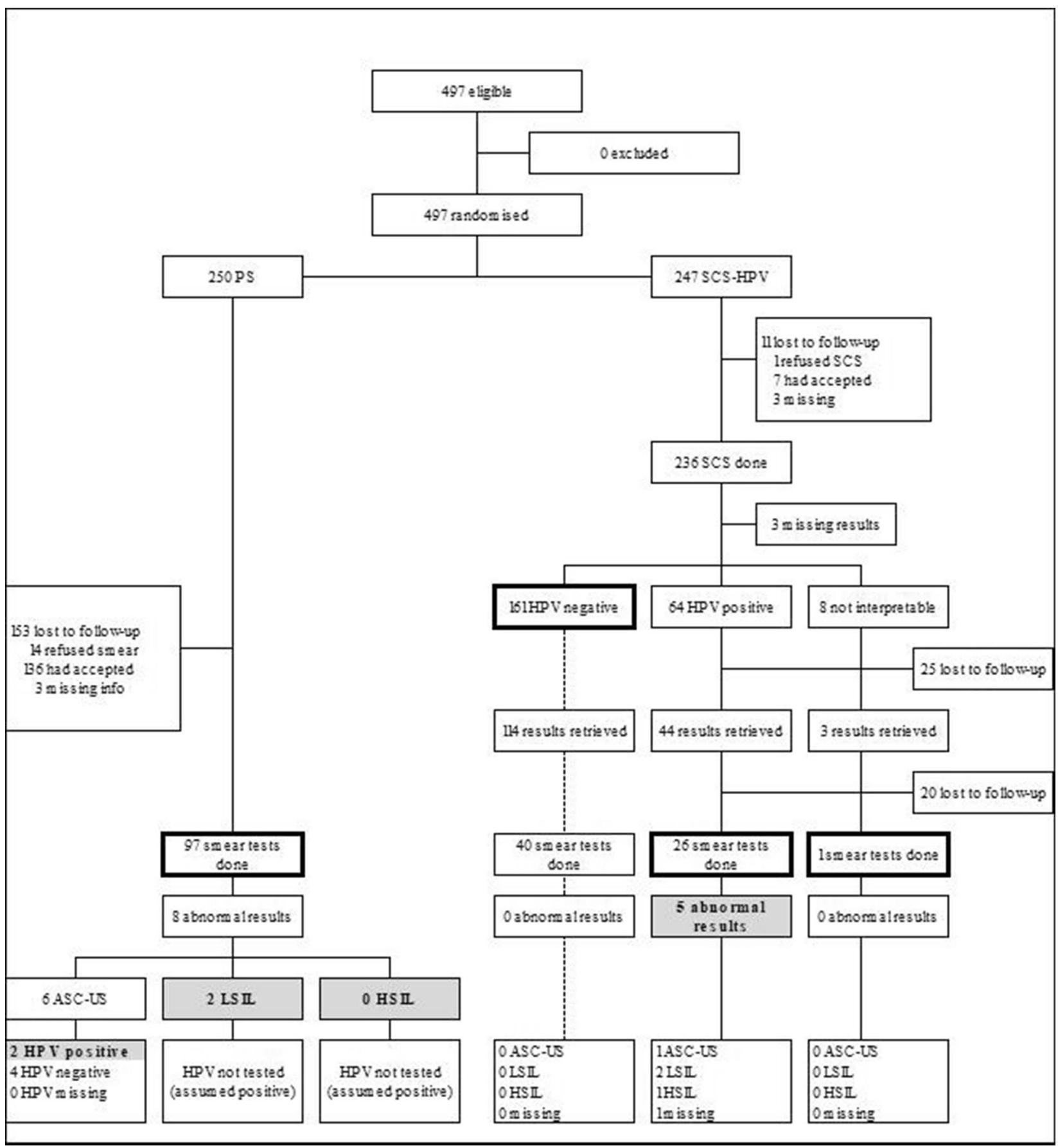


Appendix 3. Sub-group analysis using a forest plot representing the completion rate of the cervical cancer screening process, CASO and CAOA programmes only

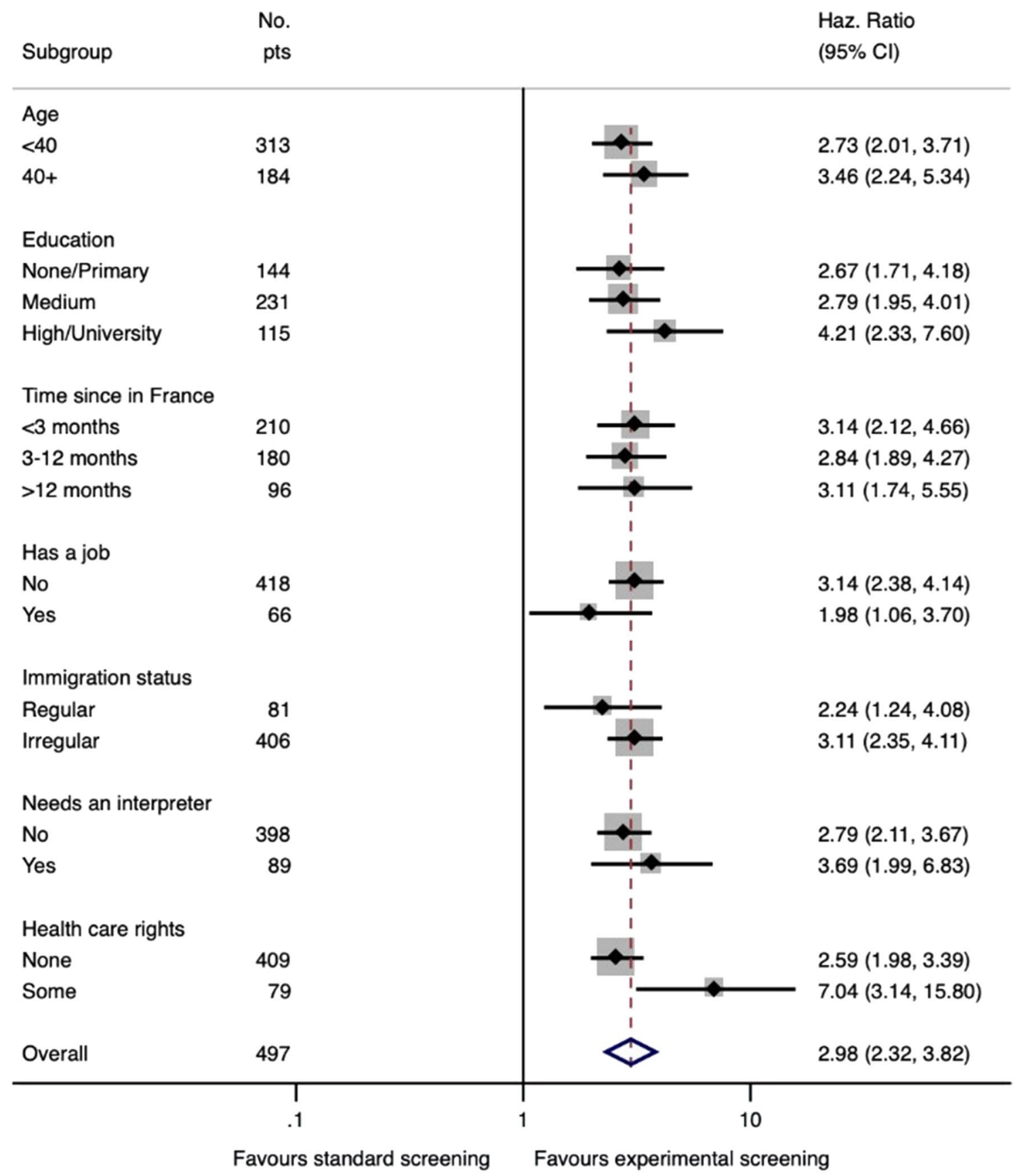

NOTE: Weighting is by sample size 


\section{Appendix 4. Sub-group analysis using a forest plot representing the detection of cytological cervical abnormalities: CASO and CAOA programmes only}

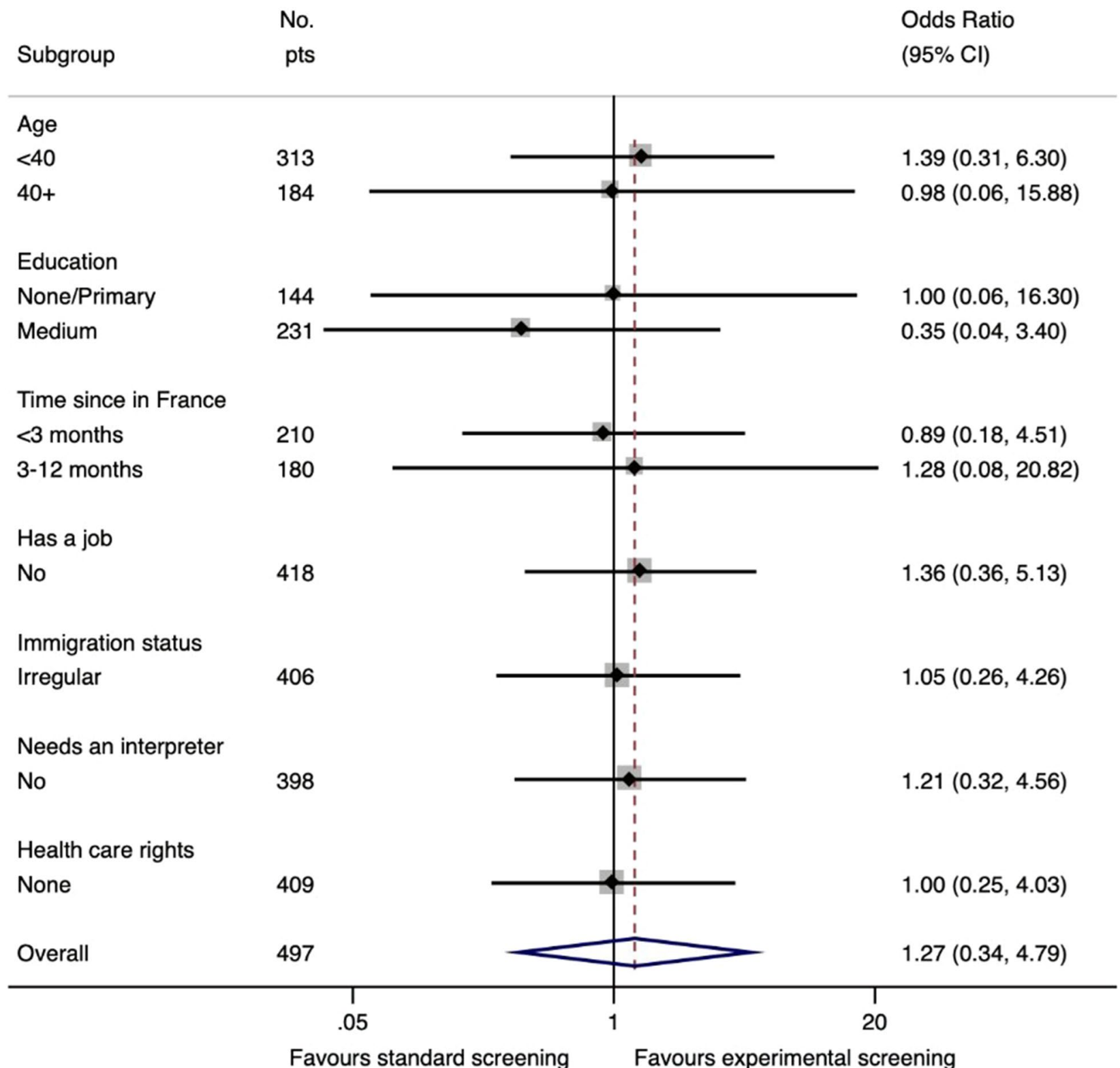

NOTE: Weighting is by sample size

Abbreviations

ASC-US: Atypical squamous cells of uncertain significance; CAOA: Centre d'Accueil, Orientation et Accompagnement; CASO: Centre d'Accueil, Soins et Orientation; CG: Control group; Cl: Confidence interval; CS: Control strategy; EG: Experimental group; ES: Experimental strategy; IRB: Institutional review board; HIV: Human immunodeficiency virus; HPV: Human papillomavirus; HR: Hazard ratio; HR-HPV: High-risk human papillomavirus; HSIL: High-grade squamous intraepithelial lesion; LSIL: Low-grade squamous intraepithelial lesion; MdM: Médécins du Monde; OR: Odds ratio; PS: Pap smear; RR: Risk ratio: SC-HPV: Self-collected human papillomavirus sample; SRH: Sexual and reproductive health; STI: Sexually transmitted infections; SWP: Sex worker's programs.
Acknowledgements

We want to thank everyone who participated in the study through the Doctors of the World programmes and to all employees and volunteers from the seven participating programmes. A special thanks as well to the study's field coordinators, D Junca, H Duberca, A Saldana, M Garcia, L Coureau, L Courret, M Foudil, P Baril, N Martin, A Merabtene, L Barda, C Nguyen, M Redonnet, AS Marie, and MC Grosdidier. Thanks to all employees from the facilities that partnered with women's and children's health centres, family planning centres, city health centres, private practise physicians, the French National Cancer Institute, Laboratoire CERBA and Dr JD Poveda, and the members of the scientific committee: V Dalstein, E Ricard, S Vandertorren, A Garnier, I Heard, and S Hugues. Thank you to all MdM staff who designed, monitored, and 
contributed to this research, including B Contamin, J Rochefort, A Tomasino, C Gutton, M Chappuis, M Laluque, V Brotons-Dias, H Merimi, S Neusy, M Mottier, and E Lyonnais.

\section{Authors' contributions}

$[\mathrm{NL}] 2,[\mathrm{AL}] 1, \mathrm{CB}, \mathrm{GL}, \mathrm{KH}, \mathrm{FH}$, and JB contributed to the design and implementation of the study. LR, [AL]1 and [NL]1 oversaw the study's implementation in the field and collected the data. LR, [AL]2, CR and EA, conducted the statistical analyses and wrote the first version of the study. All authors approved the final version. All authors read and approved the final manuscript.

\section{Funding}

Institut National du Cancer (INCA) financed the research study and materials and Médécins du Monde financed the structural costs and human resources.

\section{Availability of data and materials}

Data supporting the findings of this study are available within the article and its supplementary materials. Additional data are available from the corresponding author, upon reasonable request.

\section{Declarations}

\section{Ethics approval and consent to participate}

This research project was approved by the Île de France IV Institutional Review Board (IRB). The study was conducted in compliance with the ethical principles of the Helsinki Declaration. All participants were informed of the study's objectives and design, and their participation was voluntary after providing verbal informed consent. Verbal informed consent was approved by the IRB as the subjects were members of a distinct cultural community in which signing forms is not the norm, and the research presented no more than minimal risk or harm to subjects and provided there is an appropriate alternative mechanism for documenting that informed consent was obtained.

\section{Consent for publication}

Not Applicable.

\section{Competing interests}

The authors declare that they have no competing interest.

\section{Author details}

${ }^{1}$ Médecins du Monde, 62 rue Marcadet, 75018 Paris, France. ${ }^{2}$ EPISTATA Agency for Clinical Research and Medical Statistics, London, UK. ${ }^{3}$ Unité de Maladies Infectieuses et Tropicales, Groupe Hospitalo-Universitaire Paris Seine St-Denis, AP-HP, Hôpital Jean Verdier, Bondy, France. ${ }^{4}$ Santé Publique France (National Public Health Agency), Saint Maurice cedex, France. ${ }^{5}$ Laboratoire CERBA, Saint-Ouen-l'Aumône, France. ${ }^{6}$ U1 153, INSERM, Paris, France. ${ }^{7}$ Cancer Screening Department, CHRU de Tours, 37000 Tours, France. ${ }^{8} \mathrm{Centre}$ François Baclesse, INSERM, Avenue du Général Harris, 14076 Caen, France.

\section{Received: 16 April 2020 Accepted: 12 May 2021}

Published online: 26 May 2021

\section{References}

1. Centre National de Référence des Papillomavirus Humains (CNR HPV), Institut Pasteur. Référence des Papillomavirus Humains (CNR HPV), Institut Pasteur. In 2018. Disponible sur: www.pasteur.fr/fr/centre-medic al/fiches-maladies/cancer-du-coluterus-papillomavirus

2. Garnier A, Brindel P. Prévention et dépistage du cancer du col de l'utérus. Boulogne [Internet]. Billancourt: Institut National du Cancer; 2013. Disponible sur: www.ecancer.fr/publications/75-prevention/735-preve ntion-et-depistage-du-cancer-ducolde-luterus.

3. Institute National du Cancer. La situation du cancer en France. 2012.

4. Schiffman M, Doorbar J, Wentzensen N, de Sanjosé S, Fakhry C, Monk BJ, et al. Carcinogenic human papillomavirus infection. Nat Rev Dis Primer. 01 2016;2:16086.

5. GLOBOCAN [Internet]. Disponible sur: https://onlinelibrary.wiley.com/ doi/full/10.3322/caac.21492)
6. Estimations nationales de l'incidence et de la mortalité par cancer en France métropolitaine entre 1990 et 2018/2019/Maladies chroniques et traumatismes/Rapports et synthèses/Publications et outils/Accueil [Internet]. [cité 31 mai 2019]. Disponible sur: http://invs.santepubliquefr ance.fr/Publications-et-outils/Rapports-et-syntheses/Maladies-chron iques-et-traumatismes/2019/Estimations-nationales-de-l-incidence-etde-la-mortalite-par-cancer-en-France-metropolitaine-entre-1990-et-2018

7. Haute Autorité de Santé. Etat des lieux et recommandations pour le dépistage du cancer du col de l'utérus en France. 2010.

8. European Commission, International Agency for Research on Cancer, World Health Organization, Anttila A, Arbyn M, de Vuyst H, et al. European guidelines for quality assurance in cervical cancer screening. Second edition. Supplements. Luxembourg: European Union; 2015.

9. Hamers FF, Jezeweski-Serra D. Couverture du dépistage du cancer du col de l'utérus en France, 2012-2017. Bull Epidémiol Hebd. 2019:22-23:417-23.

10. Papillomavirus et cancer. Etat des lieux et des connaissances; Fiches repères. Institute National du Cancer; 2018.

11. Barré S, Massetti M, Leleu H, Catajar N, de Bels F. Caractérisation des femmes ne réalisant pas de dépistage du cancer du col de l'utérus par frottis cervico-utérin en France. Centre HPV; 2016.

12. Medecins du Monde. Rapport de l'Observatoire de l'accès aux droits et aux soins dans les programmes de Médecins du Monde en France en 2018. In 2019. p. 185.

13. Dalmont, C. et al. Cancer du col et précarité, accès aux soins. Bull Cancer.; 2009.

14. Sancho-Garnier H, Tamalet C, Halfon P, Leandri FX, Le Retraite L, Djoufelkit $\mathrm{K}$, et al. HPV self-sampling or the Pap-smear: a randomized study among cervical screening nonattenders from lower socioeconomic groups in France. Int J Cancer. 2013;133(11):2681-7.

15. Baay MFD, Tjalma WAA, Lambrechts HAJ, Pattyn GGO, Lardon F, Weyler J, et al. Combined Pap and HPV testing in primary screening for cervical abnormalities: should HPV detection be delayed until age 35? Eur J Cancer Oxf Engl. 2005;41(17):2704-8.

16. Leinonen, M. et al. Age-Specific Evaluation of Primary Human papillomavirus screening versus conventional cytology in randomized setting. Journal of the National Cancer Institut; 2009.

17. Arbyn M, Smith SB, Temin S, Sultana F, Castle P, Collaboration on SelfSampling and HPVTesting. Detecting cervical precancer and reaching underscreened women by using HPV testing on self samples: updated meta-analyses. BMJ. 05 2018;363:k4823.

18. Ilangovan K, Kobetz E, Koru-Sengul T, Marcus EN, Rodriguez B, Alonzo Y, et al. Acceptability and Feasibility of Human Papilloma Virus Self-Sampling for Cervical Cancer Screening. J Womens Health. 2016;25(9):944-51.

19. Fargnoli V, Petignat P, Burton-Jeangros $C$. To what extent will women accept HPV self-sampling for cervical cancer screening? A qualitative study conducted in Switzerland. Int J Womens Health. 2015;7:883-8.

20. Bonnes Pratiques Epidemiologiques. Rev. Epidemiol Santé Publ; 2008.

21. Norredam M, Nielsen SS, Krasnik A. Migrants' utilization of somatic healthcare services in Europe-a systematic review. Eur J Public Health. 2010;20(5):555-63.

22. Comparetto C, Epifani C, Manca MC, Lachheb A, Bravi S, Cipriani F, et al. Uptake of cervical cancer screening among the migrant population of Prato Province, Italy. Int J Gynaecol Obstet Off Organ Int Fed Gynaecol Obstet. 2017;136(3):309-14.

23. Taylor RJ, Mamoon HA, Morrell SL, Wain GV. Cervical screening in migrants to Australia. Aust N Z J Public Health. 2001;25(1):55-61.

24. Vuillermoz C, Chauvin P, Vandentorren $S$. Le recours au dépistage des cancers féminins dans la population sans logement personnel en llede-FranceRapport pour le Cancéropole d'lle-de-France. Observatoire du Samur sociale de Paris; 2014.

25. Rondet $C$. Déterminants de la participation au dépistage des cancers du sein et du col de l'utérus dans lagglomeration pariesienne: les origines migratoires sont un facteur d'exclusion. 2012.

26. Jackowska M, von Wagner C, Wardle J, Juszczyk D, Luszczynska A, Waller J. Cervical screening among migrant women: a qualitative study of Polish, Slovak and Romanian women in London, UK. J Fam Plann Reprod Health Care. 2012;38(4):229-38.

27. Idehen EE, Korhonen T, Castaneda A, Juntunen T, Kangasniemi M, Pietilä A-M, et al. Factors associated with cervical cancer screening participation 
among immigrants of Russian, Somali and Kurdish origin: a populationbased study in Finland. BMC Womens Health. 2017;17(1):19.

28. Bansil P, Wittet S, Lim JL, Winkler JL, Paul P, Jeronimo J. Acceptability of self-collection sampling for HPV-DNA testing in low-resource settings: a mixed methods approach. BMC Public Health. 2014;14:596.

29. Mullins R, Scalzo K, Sultana F. Self-sampling for cervical screening: could it overcome some of the barriers to the Pap test? J Med Screen. 2014;21(4):201-6.

30. Sewali B, Okuyemi KS, Askhir A, Belinson J, Vogel Rl, Joseph A, et al. Cervical cancer screening with clinic-based Pap test versus home HPV test among Somali immigrant women in Minnesota: a pilot randomized controlled trial. Cancer Med. 2015;4(4):620-31.

31. Arbyn M, Verdoodt F, Snijders PJF, Verhoef VMJ, Suonio E, Dillner L, et al. Accuracy of human papillomavirus testing on self-collected versus clinician-collected samples: a meta-analysis. Lancet Oncol. 2014;15(2):172-83.

32. Arbyn M, Castle PE. Offering Self-Sampling Kits for HPV Testing to Reach Women Who Do Not Attend in the Regular Cervical Cancer Screening Program. Cancer Epidemiol Biomark Prev Publ Am Assoc Cancer Res Cosponsored Am Soc Prev Oncol. 2015;24(5):769-72.

33. Haute Autorité de Santé. Évaluation de la recherche des papillomavirus humains (HPV) en dépistage primaire des lésions précancéreuses et cancéreuses du col de l'utérus et de la place du double immunomarquage p16/Ki67 Synthèse et recommandations. 2019.
34. Soohoo M, Blas M, Byraiah G, Carcamo C, Brown B. Cervical HPV infection in female sex workers: a global perspective. Open AIDS J. 2013;7:58-66.

35. Tornesello L, Giorgi Rossi P, Buonaguro L, Buonaguro FM. HPV Prevalence Italian Working Group. Human papillomavirus infection and cervical neoplasia among migrant women living in Italy. Front Oncol. 2014;4:31.

36. González C, Ortiz M, Canals J, Muñoz L, Jarrín I, de la Hera MG, et al. Higher prevalence of human papillomavirus infection in migrant women from Latin America in Spain. Sex Transm Infect. 2006;82(3):260-2.

37. Belinson JL, Wang G, Qu X, Du H, Shen J, Xu J, et al. The development and evaluation of a community based model for cervical cancer screening based on self-sampling. Gynecol Oncol. 2014;132(3):636-42.

38. Lim JNW, Ojo AA. Barriers to utilisation of cervical cancer screening in Sub Sahara Africa: a systematic review. Eur J Cancer Care (Engl). 2017;26(1).

39. Ndejjo R, Mukama T, Kiguli J, Musoke D. Knowledge, facilitators and barriers to cervical cancer screening among women in Uganda: a qualitative study. BMJ Open. 2017;7(6):e016282.

\section{Publisher's Note}

Springer Nature remains neutral with regard to jurisdictional claims in published maps and institutional affiliations.
Ready to submit your research? Choose BMC and benefit from:

- fast, convenient online submission

- thorough peer review by experienced researchers in your field

- rapid publication on acceptance

- support for research data, including large and complex data types

- gold Open Access which fosters wider collaboration and increased citations

- maximum visibility for your research: over $100 \mathrm{M}$ website views per year

At BMC, research is always in progress.

Learn more biomedcentral.com/submissions 